\title{
Syyskylvöisten ja monivuotisten lajien ja lajikkeiden sopeutuminen Suomen talveen - kylmänkestävyyden ja vernalisaatiovaatimuksen merkitys
}

\author{
Mervi M. Seppänen ${ }^{1)}$, Markku Niskanen ${ }^{2)}$, Venla Jokela ${ }^{1)}$, Juha Luhtanen ${ }^{1)}$, Juha Kontturi ${ }^{1)}$ ja Pirjo \\ Mäkelä ${ }^{1)}$ \\ ${ }^{1)}$ Maataloustieteiden laitos, PL 27, 00014 Helsingin yliopisto, etunimi.sukunimi@helsinki.fi, ${ }^{2)}$ MTT \\ Kasvintuotannon tutkimus, Alapääntie 104,61400 Ylistaro, etunimi.sukunimi@mtt.fi
}

\section{Tiivistelmä}

Syyskylvöisten ja monivuotisten kasvien viljelyn edellytyksenä on onnistunut talvehtiminen. Syksyn ja talven aikana kasvien kylmänkestävyys lisääntyy ja kevättä kohti myös niiden vernalisaatiovaatimus täyttyy ja kukinta virittyy. Hyvän talvehtimisen kannalta on tärkeää, että viljelykasveilla on riittävän hyvä kylmänkestävyys ja että ajoitus niiden kukinnan virittymisessä on oikea.

Tässä tutkimuksessa selvitettiin syysvehnä, -ruis ja -öljykasvilajikkeiden sekä nurmiheinien kylmänkestävyyden ja kukintavalmiuden kehittymistä Viikissä ja Ylistarossa järjestetyissä kenttäkokeissa. Tulosten perusteella vertaillaan lajien karaistumis- ja vernalisaatioprosessien etenemistä ja selvitetään lajien välisiä eroja niiden kestävyysmekanismeissa ja pohditaan vernalisaation vaikutusta viljelykasvin sadonmuodostukseen.

Syksyn karaistumisajan pituus vaikutti ratkaisevasti lajin ja lajikkeen perinnöllisen kylmänkestävyyden ilmenemiseen. Kylmänkestävyys jäi siten heikoksi kaikilla lajeilla syysrypsiä lukuun ottamatta aikaisen lumentulon johdosta. Tutkittavat viljelykasvit poikkesivat huomattavasti niiden kukkimisvalmiuden etenemisessä talven aikaan. Syysvehnällä kukkimisvalmiuden eteneminen oli yhteydessä alentuneeseen kylmänkestävyyteen ja vernalisaatiovaatimuksen täyttyminen pystyttiin mittaamaan muodostuneiden lehtien lukumäärän kautta. Nurmikasveilla vernalisaatiovaatimuksen täyttyminen vaikutti muodostuvien versojen lukumäärään. Vaikutus oli päinvastainen ruokonadalla verrattuna timoteihin tai englannin raiheinään. Tutkimuksen tulosten sekä meneillään olevien jatkotutkimusten perusteella analysoidaan, miten talven aikana tapahtuva vernalisaatio vaikuttaa lajin kylmänkestävyyteen sekä satopotentiaaliin.

Avainsanat englannin raiheinä, festulolium, kylmänkestävyys, nurminata, ruokonata, syysruis, syysrypsi, syysvehnä, timotei, vernalisaatio 


\section{Johdanto}

Ilmastonmuutos on globaalisti yksi elintarviketuotannon suurimpia haasteita. Keskilämpötila tulee nousemaan ja viljelykasveille käyttökelpoinen kasvukausi pitenemään. Kasvukauden pidentyminen, talvien leudontuminen ja kesän kuivuusjaksojen yleistyminen lisäävät syyskylvöisten viljojen ja öljykasvien viljelyn kiinnostavuutta. Lyhentynyt ja leudontunut talvi puolestaan mahdollistaa talvenkestävyydeltään heikompien viljelykas vilajien ja -lajikkeiden menestymisen Suomessa.

Onnistuneen talvehtimisen edellytyksenä kuitenkin on, että viljelykasvi ehtii kylmäkaraistua ja parantaa kylmänkestävyyttään riittävästi syksyllä. Lajin tai lajikkeen tulee olla myös sopeutunut Suomen talven pituuteen, jotta saavutettu kylmänkestävyys pysyisi riittävänä pitkän talven ajan. Talven aikana kylmänkestävyys purkautuu asteittain ja viljelykasvit saavuttavat valmiuden muodostaa kukintoja (Fowler ym. 1996). Nurmikasveilla vernalisaatio havaitaan keväällä kasvuston nopeana kehittymisenä sekä alempana versolukumääränä (Seppänen ym. 2010). Syyskylvöiset viljelykasvit tarvitsevatkin kylmäkokemisen eli vernalisaation, jotta kukinta ja sadon muodostuminen olisi mahdollista. Sekä kylmänkestävyys että vernalisaatiovaatimus ovat kasvin perimän säätelemiä ominaisuuksia ja ne ovat ratkaisevassa asemassa syyskylvöisten viljelykasvien onnistuneelle talvehtimiselle Suomessa. Myös valojakson pituus ja valon määrä ovat viljelykasveille tärkeitä ympäristön signaaleja, jotka ohjaavat niin karaistumis- kuin vernalisaatioprosesseja (Distelfeld ym. 2009).

Tässä tutkimuksessa selvitettiin syysvehnä, -ruis ja -öljykasvilajikkeiden sekä nurmiheinien kylmänkestävyyden ja kukintavalmiuden kehittymistä Viikissä ja Ylistarossa järjestetyissä kenttäkokeissa. Tulosten perusteella vertaillaan lajien karaistumis- ja vernalisaatioprosessien etenemistä ja selvitetään lajien välisiä eroja niiden kestävyysmekanismeissa. Jatkotutkimuksissa fysiologisten prosessien eteneminen yhdistetään tärkeimpien vernalisaatio- ja kylmänkestävyysgeenien ilmenemiseen. Tulokset auttavat kasvinjalostajia kohdentamaan jalostustoimet lajin kannalta kriittisiin ominaisuuksiin.

\section{Aineisto ja menetelmät}

Kenttäkokeet järjestettiin Helsingin yliopiston Viikin opetus- ja tutkimustilalla (2009-2011) sekä MTT Ylistaron tutkimusasemalla (2010-2011). Kokeissa mukana olleet lajit ja lajikkeet on esitetty Taulukossa 1. Eri koepaikoilla testatut lajit ja lajikkeet esitetään tulosten yhteydessä.

Taulukko 1.Pelto- ja kasvatuskaappikokeissa tutkitut lajit, lajikkeet tai linjat.

\begin{tabular}{|l|l|}
\hline Laji & Lajike \\
\hline Syysvehnä & Magnifik, Olivin, Urho, Artika \\
\hline Syysruis & Kier, Riihi, Reetta, Evolo \\
\hline Syysrypsi & Largo, Rapido, Kulta, Salut \\
\hline Timotei & $\begin{array}{l}\text { Iki, Tuure, Tammisto II, Tia, Tika, Grindstat, BOR01025, } \\
\text { Jonathan, BOR0113, BOR0307, B112, 21/1, Tanskan linjat }\end{array}$ \\
\hline Englannin raiheinä & Riikka, SW Birger, Svea \\
\hline Nurminata & Ilmari \\
\hline Ruokonata & Retu, Kora, Karolina \\
\hline Festulolium & Felina, Lofa \\
\hline
\end{tabular}

Kasvien kylmänkestävyyden ja kukintavalmiuden kehittymistä seurattiin loka-marraskuun välisenä aikana. Mittausta varten kasvinäytteitä kerättiin pellolta kerran kuukaudessa ja kasvien kylmänkestävyys $\left(\mathrm{LT}_{50}=\right.$ lämpötila, jossa $50 \%$ kasveista on kuollut) testattiin kylmähauteessa. Kylmäkäsittelyn jälkeen kasvien elävyyttä seurattiin kasvihuoneessa kunnes muutoksia ei enää tapahtunut. Kasvatuksen aikana havainnoitiin kukkimispäivämäärä (kaikki lajit) sekä mitattiin korkeus ylimpään kielekkeseen (timotei). Kokeen päätyttyä laskettiin lehtien (kaikki lajit) sekä versojen (nurmikasvit) lukumäärä. Syysrypsin kylmänkestävyys määritettiin joko tetrazolium-värjäyksellä (MTT) tai ionivuototestillä (Viikki).

\section{Tulokset ja tulosten tarkastelu}

Timotein talvehtimista seurattiin talvien $2009-2010$ ja 2010-2011 aikana, muilla lajeilla esitetyt tulokset ovat vuodelta 2010-2011. Syksyn aikana kertyneiden karaistumispäivien lukumäärä vaikutti merkittävästi 
mitattuun kylmänkestävyyteen. Molempina talvina timotein kylmänkestävyys jäi melko vaatimattomaksi ollen esimerkiksi Ikillä alimmillaan $-14{ }^{\circ} \mathrm{C}$ vuonna 2009 ja $-10{ }^{\circ} \mathrm{C}$ vuonna 2010. Talvella 2010-2011 kaikkien tutkittujen kasvien kylmänkestävyys oli heikko: esimerkiksi rukiin kylmänkestävyys oli alimmillaan vain $-11^{\circ} \mathrm{C}$ (Viikki) ja $-10^{\circ} \mathrm{C}$ (Ylistaro). Vastaavalla pakkaskäsittelyn jälkeen tapahtuvalla jälleenkasvun arvioinnilla on parhaimpien syysvehnä ja -ruislajikkeiden kylmänkestävyydeksi mitattu kontrolloiduissa oloissa $-25^{\circ} \mathrm{C}$ (Fowler ym. 1996). Koska lumipeite säilyi Viikissä huhtikuun alkupäiviin saakka, onnistui talvehtiminen kuitenkin hyvin. Tammi-maaliskuussa 2011 mitattiin syysrypsin kylmänkestävyydeksi ionivuototestillä jopa $-25^{\circ} \mathrm{C}$. Kylmänkestävyys purkautui huhtikuussa, jolloin havaittiin myös hienoisia lajikkeiden välisiä eroja. Toukokuussa kylmänkestävyys oli enää noin $-12^{\circ} \mathrm{C}$ kaikilla syysrypsilajikkeilla.

Syysvehnällä lehtien lukumäärän aleneminen kuvasi hyvin kukkimisvalmiuden täyttymistä, mikä oli puolestaan yhteydessä kylmänkestävyyden alenemiseen (Kuva 1a). Sen sijaan rukiilla kukkimisvalmius säilyi muuttumattomana koko talven ja tähkiä muodostui kasvihuoneessa 30-50 vuorokauden jälkeen näytteenottokuukaudesta tai paikasta riippumatta. Syysviljoilla vernalisaatiovaatimuksen täyttymisen ja kylmänkestävyyden alenemisen yhteys on aiemmin raportoitu niin kontrolloiduissa oloissa (Kane ym. 2005) kuin kenttäkokeissakin (Mahfoozi ym. 2005). Tässä tutkimuksessa syysvehnälajikkeet saavuttivat kukkimisvalmiuden Viikissä helmikuuhun ja Ylistarossa maaliskuuhun mennessä. Fowler ym. (1996) raportoivat kontrolloiduissa oloissa suoritetun tutkimuksen perusteella syysvehnän ja -rukiin reagoivan samalla tavoin vernalisaation täyttymiseen. Tämän kokeen alustavien tulosten perusteella voidaan vasta arvella, että karaistumisajan lyhyys on voinut vaikuttaa rukiin lepotilan syvyyteen.

Nurmilla sen sijaan versojen lukumäärän aleneminen kuvasi lehtien lukumäärää paremmin kukkimisvalmiuden kehittymistä (Kuva 1b). Nurmikasvilajeista englannin raiheinällä versojen lukumäärä aleni merkittävästi talven aikana kun muutokset timoteillä ja nurminadalla olivat vähäisempiä. Ruokonata ja Festulolium poikkesivat täysin muista nurmiheinistä, niillä versojen lukumäärä lisääntyi keväällä.
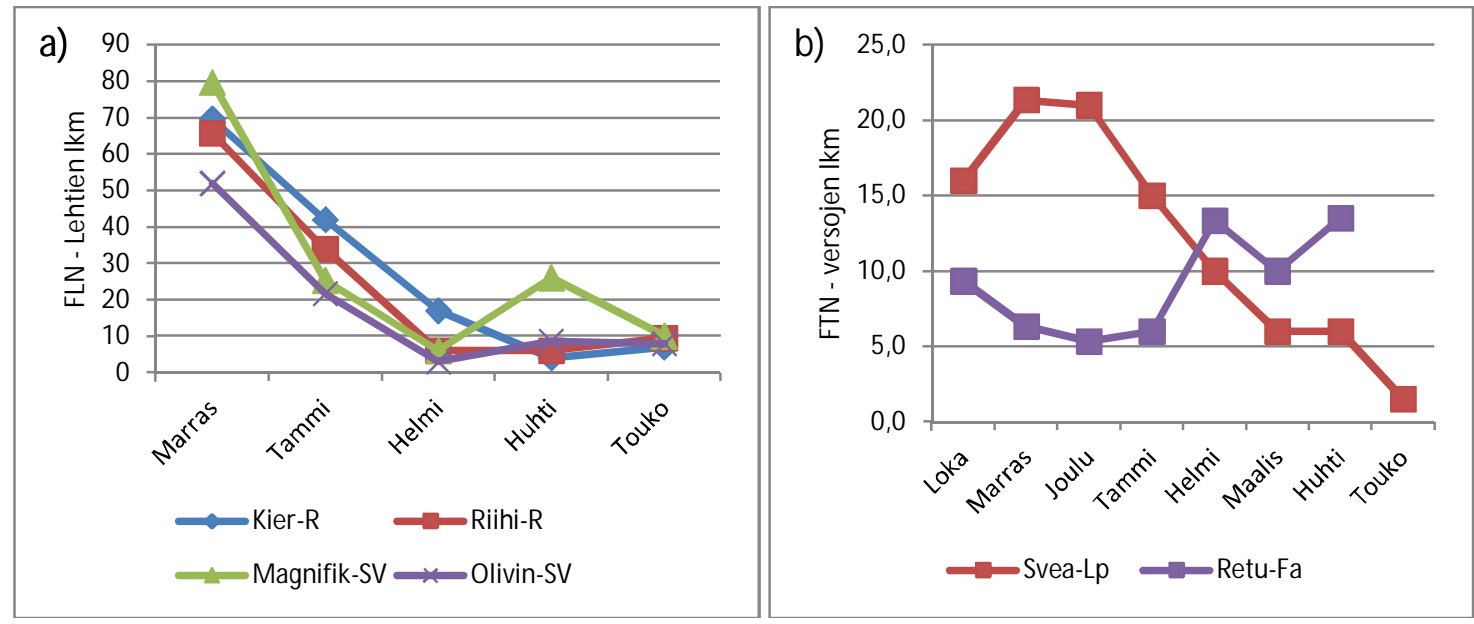

Kuva 1. a) Lehtien lukumäärä syysvehnällä (Magnifik, Olivin) ja -rukiilla (Kier, Riihi) sekä b) versojen lukumäärä englannin raiheinällä (Svea) ja ruokonadalla (Retu) noin 50 vuorokautta näytteenoton jälkeen Viikissä talvella 20102011.

Vernalisaatio nopeuttaa nurmikasvien kehitystä ja kukintaa sekä johtaa versojen lukumäärän alenemiseen (Seppänen ym. 2010). Timoteillä lajikkeet voidaan jakaa karkeasti eteläisiin ja pohjoisiin (Isolahti 2010), joista eteläiset (Grindstat, BOR 01025) eivät vaatineet pituuskasvun vapautumiseen vernalisaatiota (Kuva 2). Sen sijaan pohjoisista lajikkeista Ikin pituuskasvu nopeutui vasta tammikuussa, samaan aikaan kuin kukintavalmius oli saavutettu. Pitkä talvi johti erittäin nopeaan kevätkasvuun, jonka seurauksena kasvien korkeus jäi matalaksi ja versojen lukumäärä alhaiseksi. Siten timotein satopotentiaalia menetettiin talven aikana. 


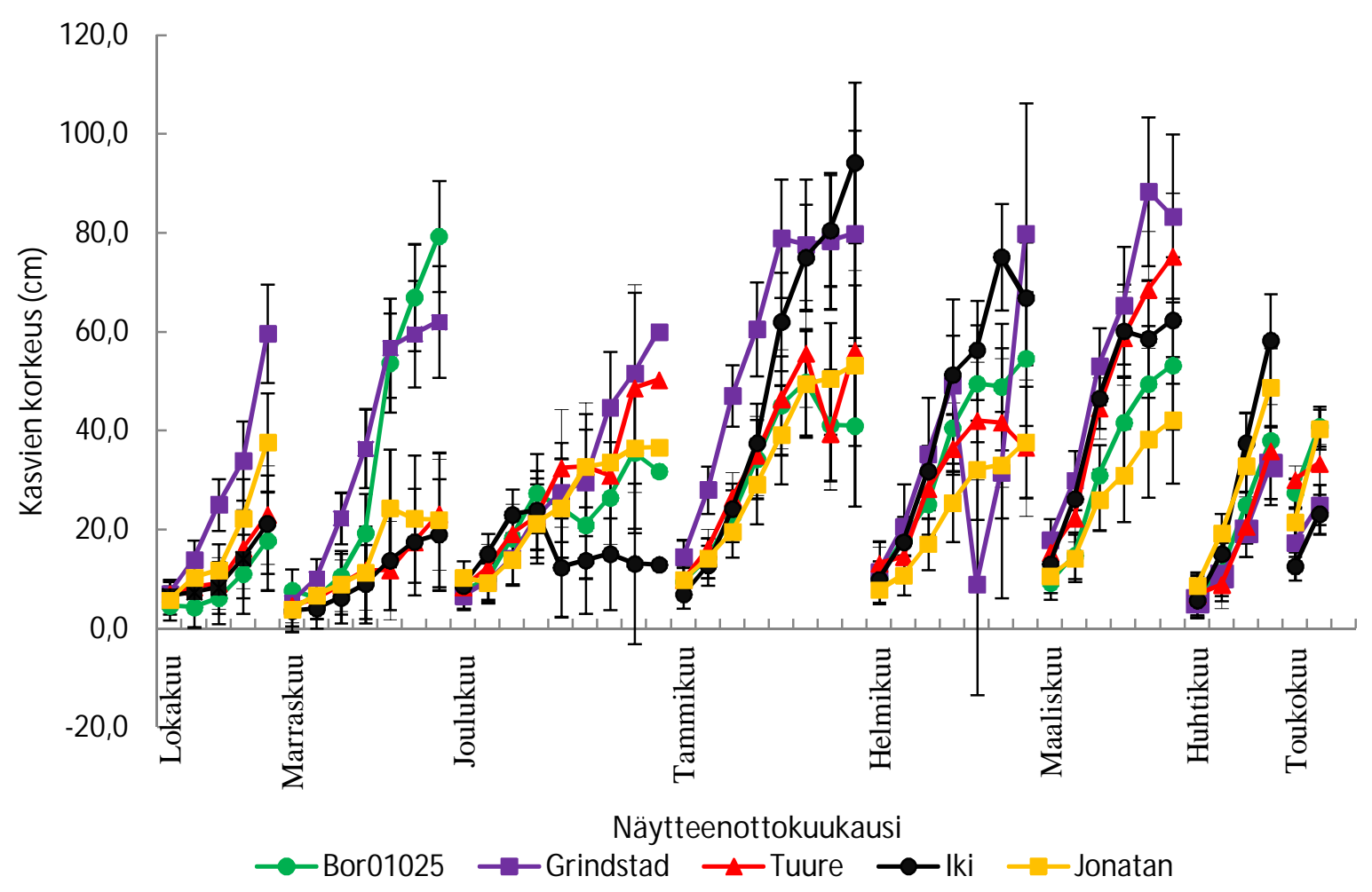

Kuva 2. Timotein kasvunopeus ja kasvien lopullinen korkeus talvella 2010-2011 kasvihuoneeseen siirron jälkeen.

\section{Johtopäätökset}

Syksyn karaistumisajan pituus vaikutti ratkaisevasti lajin ja lajikkeen perinnöllisen kylmänkestävyyden ilmenemiseen. Kylmänkestävyys jäi siten heikoksi kaikilla lajeilla syysrypsiä lukuun ottamatta aikaisen lumentulon johdosta. Tutkittavat viljelykasvit poikkesivat huomattavasti niiden kukkimisvalmiuden etenemisessä talven aikaan. Syysvehnällä kukkimisvalmiuden eteneminen oli yhteydessä alentuneeseen kylmänkestävyyteen ja vernalisaatiovaatimuksen täyttyminen pystyttiin mittaamaan muodostuneiden lehtien lukumäärän kautta. Nurmikasveilla vernalisaatiovaatimuksen täyttyminen vaikutti muodostuvien versojen lukumäärään. Vaikutus oli päinvastainen ruokonadalla verrattuna timoteihin tai englannin raiheinään. Tutkimuksen tulosten sekä meneillään olevien jatkotutkimusten perusteella analysoidaan, miten talven aikana tapahtuva vernalisaatio vaikuttaa lajin kylmänkestävyyteen sekä satopotentiaaliin.

\section{Kiitokset}

Tutkimusryhmä kiittää lämpimästi Oiva Kuusiston Säätiötä, Niemen Säätiötä sekä Kasvinjalostus Boreal Oy:tä tutkimuksen tukemisesta.

\section{Kirjallisuus}

Distelfeld, A., Li, C., Dubcovsky, J. 2009. Regulation of flowering in temperate cereals. Current Opinions in Plant Biology 12:178-184.

Fowler, D. B., Limin, A. E., Wang ShiYing., Ward, R. W. 1996. Relationship between low-temperature tolerance and vernalization response in wheat and rye. Canadian Journal of Plant Science 76 (1): 37-42.

Isolahti 2010. Timotein maantieteelliset geenipoolit ja niiden käyttö jalostusohjelmissa. Teoksessa: Maataloustieteen Päivät 2010. 2010. Suomen Maataloustieteellisen Seuran julkaisuja numero 26. Toimittanut Anneli Hopponen.http://www.smts.fi/jul2010/esite2010/049.pdf Viitattu 21.6.2011 
Kane, N. A. Danyluk, J. Tardif, G. Ouellet, F. Laliberte, J. F. Limin, A. E. Fowler, D. B. Sarhan, F. 2005. TaVRT-2, a member of the StMADS-11 clade of flowering repressors, is regulated by vernalization and photoperiod in wheat. Plant Phys. 138: $2354-2363$.

Mahfoozi, S., Limin, A. E., Ahakpaz, F. Roustail, M., Ketala, H. \& Fowler, D. B. 2005. Regulation of low-temperature tolerance in barley under field conditions in northwest Iran. Canadian J. Plant Sci. 85:587-592.

Seppänen, M. M., Pakarinen, K., Jokela, V., Andersen, J. R., Fiil, A., Santanen, A. \& Virkajärvi, P. 2010. Vernalization response of Phleum pratense and its relationships to stem lignification and floral transition. Annals of Botany 106 (5): $697-707$. 